\title{
Inquiry-based course in physics and chemistry for preservice K-8 teachers
}

\author{
Michael E. Loverude, ${ }^{1}$ Barbara L. Gonzalez, ${ }^{2}$ and Roger Nanes ${ }^{1}$ \\ ${ }^{1}$ Department of Physics, California State University Fullerton, Fullerton, California 92834, USA \\ ${ }^{2}$ Department of Chemistry and Biochemistry, California State University Fullerton, Fullerton, California 92834, USA
}

(Received 13 November 2009; revised manuscript received 17 November 2010; published 2 May 2011)

\begin{abstract}
We describe an inquiry-based course in physics and chemistry for preservice K-8 teachers developed at California State University Fullerton. The course is one of three developed primarily to enhance the science content understanding of prospective teachers. The course incorporates a number of innovative instructional strategies and is somewhat unusual for its interdisciplinary focus. We describe the course structure in detail, providing examples of course materials and assessment strategies. Finally, we provide research data illustrating both the need for the course and the effectiveness of the course in developing student understanding of selected topics. Student responses to various questions reflect a lack of understanding of many relatively simple physical science concepts, and a level of performance that is usually lower than that in comparable courses serving a general education audience. Additional data suggest that course activities improve student understanding of selected topics, often dramatically.
\end{abstract}

DOI: 10.1103/PhysRevSTPER.7.010106

PACS numbers: 01.40.J-

\section{INTRODUCTION}

In the midst of ongoing national debates about education, there has been increased attention to the role of science departments in the preparation of preservice teachers. In the recent past, preparation of teachers, particularly those in lower grades, focused on general teaching strategies or "methods" without specific attention to the subject matter context in which they would be implemented. Science departments rarely paid any special attention to preservice teachers, viewing their preparation as the duty of education programs, and these students were rarely tracked or even noticed in courses serving broader student populations. However, as concerns arose about the general state of science education in K-12, many in the science disciplines have pointed out the importance of content knowledge for teachers, and the fact that science departments are best qualified to influence this content knowledge. In California, as elsewhere, teaching science content is the responsibility of science departments, not of the college of education. And yet, until recently, most science content departments paid little attention to the special needs of preservice teachers. The role of science departments in the preparation of teachers has grown to be an important focus of professional societies and faculty in the physical sciences [1].

It should be noted that there is little conclusive evidence of the impact of teacher content knowledge on student achievement in science. The published research is at best

Published by the American Physical Society under the terms of the Creative Commons Attribution 3.0 License. Further distribution of this work must maintain attribution to the author $(s)$ and the published article's title, journal citation, and DOI. ambiguous, as noted by Wilson et al. [2], and what research there is typically does not directly measure teacher content knowledge, rather using markers like courses and degrees completed [2]. For example, Goldhaber and Brewer performed an econometric analysis on the NELS:88 data set that linked students to specific classes and teachers, finding that teachers with baccalaureate degrees in science were associated with higher student science test scores [3]. In a later study, though, Goldhaber and Brewer reported no impact of science degrees on student achievement. Other studies provide similarly contradictory signals [4]. In one widely cited study, Monk found a positive and statistically significant relationship between the number of science and math courses taken by teachers and gains in student performance, though with diminishing marginal returns or threshold effects [5]. Confounding this result, Monk also reported for sophomore students enrolled in a high school physical science course a negative relationship between the count of undergraduate physical science courses taken by a teacher and student performance on the National Assessment of Educational Progress in science.

Several authors have also suggested that preparing teachers requires more than just content knowledge, but also attention to pedagogical issues that are disciplinespecific. Shulman supports the importance of subject matter knowledge in the preparation of elementary teachers, but further argues that subject matter knowledge must be integrated with discipline-specific "pedagogical content knowledge [6]." In the context of mathematics, Ball and others have developed this idea further, with one study showing connections between teacher scores on a measure of "mathematical knowledge for teaching" and student gain scores [7]. 
In light of the importance of subject matter knowledge, it is troubling to note how little experience many $\mathrm{K}-8$ teachers have with certain disciplines, particularly math and the physical sciences [8]. We have performed surveys of students in courses for preservice teachers at our university in which they were asked to report all high school science courses $(N=124)$. While the data do not constitute a formal study of student content knowledge, they do give some sense of student science preparation. About $20 \%$ of the students reported a strong background including three or more years of science with at least one honors or advanced placement (AP) course. Only a third of the students reported taking any high school physics course. In addition, $40 \%$ reported only two years of high school science, the bare minimum to satisfy requirements. A review of courses taken by multiple-subject credential candidates at our university between Spring 2005 and Spring 2009 shows similar trends, revealing that at best $20 \%$ had completed a college physics or chemistry course [9]. Even if preservice teachers do take science content courses, the research on what most students learn in those courses is not encouraging [10]. In this paper we describe one local response to these issues.

\section{LOCAL ENVIRONMENT AND CONSTRAINTS}

Any curricular change is of necessity situated in a local context, and the context will impose constraints and challenges. In some cases, the issues will be of a general nature so that solutions can be widely generalizable. Other constraints are likely to be idiosyncratic and a function of local circumstances that are not likely to be repeated in other institutions. California has a number of specific requirements for preservice teachers that may be unusual.

\section{A. California State University Fullerton (CSUF) environment}

California State University Fullerton (CSUF) is a regional comprehensive university in southern California. CSUF primarily serves students from Orange, Los Angeles, and San Bernardino counties. With 36262 students as of Fall 2009, CSUF has the largest enrollment of the 23 campuses in the California State University (CSU) system, and the second-largest enrollment of all California universities. Until recently, the CSU system by state law did not offer doctoral degrees; a joint doctoral program offered by San Diego State University in partnership with University of California San Diego is a notable exception. In 2005, a state law was passed that allows the CSU system to offer Ed.D. degrees, and CSUF is one of several campuses that offers the Ed.D. in educational leadership. CSUF, like most of the CSU campuses, offers bachelor's and master's degrees in a wide variety of fields including all of the sciences and mathematics.

\section{B. State requirements for teacher preparation}

In California, students seeking to teach grades $\mathrm{K}-8$ pursue what is known as a multiple-subject credential. Undergraduate students do not major in education. Rather, they complete a bachelor's degree in a content discipline, typically Liberal Studies or Child and Adolescent Studies, and then enter a postbaccalaureate credential program. In order to qualify for the credential program, prospective teachers are required to master a series of content standards as articulated in a series of state documents [11]. Mastery of these standards is demonstrated by completion of a series of courses and/or standardized multiple-choice examination(s) [12]. Typically students complete lower-division courses in several disciplines, with each university offering different courses that meet these requirements. Most of these courses exist so that students may fulfill general education (GE) requirements and are not particularly targeted toward preservice teachers. The courses tend to be traditionally taught in large lecture settings, with little opportunity for interaction or discussion.

At CSUF, general education requirements for all students include one course in biology, one in a physical or Earth science, and one lab in any science. Students preparing for a multiple-subject credential have to satisfy additional requirements and typically take three lower-division courses, one each in biology, physical science, and Earth and space science, plus one upper-division course in either life or physical science. Students admitted to the fifth-year multiple-subject credential program often come from other four-year schools with different requirements and may not have completed all of the science courses. These three science content areas do not perfectly match the departmental structure in most universities, but they are tailored to California's K-12 science standards, particularly those for grades 6, 7, and 8, which cover Earth science, life science, and physical science, respectively. In particular, physical science standards include both physics and chemistry content, a matter that has particular implications for this work.

\section{Undergraduate reform initiative}

The willingness of science content faculty at CSUF to focus on nontraditional instructional strategies did not develop overnight. A gradual evolution of interest began in the early 1990s, with an increasing awareness of the results of discipline-based education research and the reformed pedagogy resulting from this research. Several members of the faculty of the College of Natural Sciences and Mathematics (NSM) at CSUF developed an interest in reforming the teaching of lower-division science courses. The Physics Department participated in several NSF-funded projects in this vein: CSUF shared oversight with Cal Poly Pomona for the Southern California Alliance of Mentors for Physics Instruction [13], was a test site for 
the Physics in Context curriculum developed as part of the Introductory University Physics Project (IUPP) [14], and was a participating site for the NSF-funded Constructing Physics Understanding Project (CPU) directed by Dr. Fred Goldberg at San Diego State University [15].

As the interest in the teaching and learning of science developed, several faculty in the College of NSM sought a means of institutionalizing reform. The College was awarded a grant from the National Science Foundation for the Undergraduate Reform Initiative (URI). The URI sought to reform the teaching and learning of science for GE and preservice teacher education courses as well as courses taken by science majors. Working groups were created to focus on these different student populations. At the same time, the entire university underwent a multiyear reevaluation of its GE program, leading to student learning goals in science, math, and technology that were phrased in terms of objectives more closely linked to assessment (as opposed to broader and more vague statements of purpose). This effort created an opportunity to revise existing courses and develop new ones that were aligned with the newly developed learning goals. The initial efforts of the URI working group to reform foundation courses led to the nationally recognized reform of the entire curriculum in the Department of Biological Science [16].

\section{Project ConCEPT}

Coincident with the URI, Roger Nanes developed an NSF-funded project titled Contextual Coursework for Elementary Pre-Service Teachers (ConCEPT). ConCEPT was a collaborative effort with five local community colleges to develop inquiry-oriented lab-based courses in the sciences for future elementary teachers that would be better matched than traditional lecture courses to the special needs of this unique population. The primary pedagogical goals of ConCEPT were (1) to focus on the nature of scientific inquiry, i.e., how to pose questions, gather evidence and draw conclusions based on evidence, (2) to model collaborative instructional methods adaptable to the elementary classroom, and (3) to break from traditional theoretical and abstract science courses and focus on teaching science in the context of real-world, interdisciplinary problems.

The three ConCEPT courses were intended to serve as a required nine-unit cross-disciplinary package that would fulfill science content requirements for entry to a multiplesubject teaching credential and provide a strong disciplinary background in biology, Earth science, physics, and chemistry. Two of the courses, "Biology for Future Elementary Teachers" and "Earth/Astronomical Science for Future Elementary Teachers" were developed as single-discipline courses, but Physics/Chemistry 102, "Physical Science for Future Elementary Teachers" (hereafter referred to as Phys/Chem 102), is taught jointly by two departments, Physics and the Department of Chemistry and Biochemistry. This structure was motivated by the fact that GE science requirements at CSUF are, as noted above, divided between the categories physical science, Earth and astronomical science and life science, and that content standards for teachers and K-12 students follow a similar split. In Phys/Chem 102, one instructor from each department is typically assigned to the course, though one or both may be a part-time lecturer. In a few instances at CSUF, graduate students with career goals as teachers have been assigned to teach the course, but have been paired with a faculty member with experience in the course.

Each of the three ConCEPT courses is taught in a weekly six-hour lab format. There is typically no lecture; rather, students work in small groups on carefully structured learning activities. Because of the lab format, enrollment is limited to 26 students per section, compared to the 75-125 student lectures common to the more traditional general education courses in these departments. Some content for these courses was adapted from national curricula and some was developed locally, often in collaboration with two-year college faculty from the partner institutions [17]. While the biology and geology courses have their own compelling story lines, the focus for the remainder of this paper will be on the physical science course, Phys/Chem 102 [18].

ConCEPT emphasized learning science in context, a focus that was influenced by the Physics in Context thread of IUPP as well as the American Chemical Society's Chemistry in Context curriculum [19]. Each of the courses was developed to include two or more story lines that would motivate the introduction of relevant science content. The intention is that students will see science as an interconnected discipline with real-world implications rather than a collection of facts and equations. For Phys/ Chem 102 three contexts were chosen: global warming, focusing on the physics and chemistry of climate change, including heat and temperature as well as the interaction of light and matter; kitchen science, focusing on everyday aspects of chemistry and some additional topics from thermal physics, such as phase transitions and specific heat; and the automobile, focusing on kinematics, dynamics, and electricity and magnetism. Each topic is rich with difficult content, and could easily occupy a full semester or more, but the units focus on introductory science that meets the California content standards. The duration of the units vary according to the topics that the course instructors select.

In order to maintain a balance between some of the more difficult concepts demanded by the story line and teaching scientific fundamentals, the curriculum proceeds with simple first attempts at answering basic questions. As concepts are introduced and developed, the story line is refined by adding more sophisticated concepts. For 
example, the story line for the global warming context begins with a diagrammatic approach to energy storage, transfer, and transformation using multiple representations [20]. It then proceeds to simple water mixing experiments, the analysis of which leads students to the fundamental differences between heat and temperature [21]. Students then conduct an important experiment that serves as a benchmark for later activities. They heat a black can containing water with a $100-\mathrm{W}$ light bulb and record the temperature of the water from room temperature to thermal equilibrium, constructing a temperature-time graph. They also conduct a related experiment to produce a temperature-time graph for cooling of nearly boiling water in the same can. Students analyze the two graphs in order to generate the idea that the can must be radiating energy even in the heating experiment and formulate the concept of a dynamic equilibrium as a balance between the rates of energy input and radiated energy output.

After this benchmark experiment, students imagine how the experiment would differ if, for example, an insulator were wrapped around the heated can. The story line now spirals back and uses the black can experiment as a model in order to examine the thermal equilibrium of a "naked" Earth with no atmosphere- the light bulb is analogous to the Sun and the water can is analogous to the radiating Earth.

The story line then introduces the electromagnetic spectrum and attempts to refine the model attained thus far by considering the effects of spectral absorption by the atmosphere. Students first consider color formation by plastic filters as a simple model for spectral absorption. The atmosphere can then be compared to the insulator around the can considered in an earlier activity. Atmospheric absorption by greenhouse gases is related to prior activities involving absorption by colored plastic filters, leading to discussion of the greenhouse effect and its effect on global energy balance.

In principle, the contextual approach has the advantage of presenting concepts as needed, and we feel that the approach closely emulates the scientific process, with continual refinement of explanatory models. Consequently, students can more readily perceive the evolutionary and empirical nature of scientific endeavor. On the other hand, the context does sometimes require the introduction of content that is quite difficult for students. Previous research on the IUPP courses suggested that many students lost track of the story line or were dissatisfied at the level of resolution provided [22].

\section{PHYSICS/CHEMISTRY 102}

In this section, we will describe the course in some detail, including the course structure, pedagogical approach, course materials, and assessment strategies.

\section{A. Course structure and pedagogy}

Phys/Chem 102 is different from standard lecture courses, but is similar in structure to other lab-based inquiry-oriented courses. Students meet for six hours in either three two-hour or two three-hour meetings per week. (In the discussion that follows, one "hour" is really 50 minutes of class time.) The class is designated by the university as an activity format, so students receive three units, or one for every two class hours. This format is intermediate between lecture ( 1 credit per class hour) and lab ( 1 credit per 3 class hours). As noted above, GE requirements for all students include one course in biology, one in a physical or Earth science, and one lab in any science; Phys/Chem 102 can be an attractive option for students as the one course fulfills both the physical science and laboratory requirements.

All class activities take place in a dedicated lab classroom. There are six fixed tables in the room; each seats four or five students and has its own sink, gas, and electrical connections. The course does not formally incorporate any lecture instruction, and the intention is that most classroom time will involve students working together in small groups; the tables naturally group students into pairs but are angled to allow pairs to discuss as a whole table group. At the same time, the shape and orientation of the tables, and the fact that student seats are on wheels, allow students to face the front of the room, allowing short lectures or whole-class discussions. Enrollment in each class is capped at 26, divided equally between students enrolled in a section designated as Chemistry 102 and one designated as Physics 102, both scheduled for the same time and room. There is no practical difference between the two, as either satisfies the physical science GE requirement. In its inaugural semester, Spring 1999, only one class was offered, and enrollment increased steadily to a steady state of four classes per semester until Fall 2008, when two were cut due to severe statewide budget cutbacks.

While Phys/Chem 102 is not a methods course, the course does seek to model the way science can be taught in the elementary school where lecture is not a desirable option, i.e., with small-group hands-on activities and discussion, with very little whole-class lecture or discussion. The pedagogical philosophy of the course was influenced by curricula like Physics by Inquiry, and Powerful Ideas in Physical Science [23] as well as state and national standards for science education [24]. Activities include experimental measurements and other hands-on activities, as well as small-group discussions of pencil-and-paper activities. In a variety of activities, student groups prepare whiteboards to present their analysis of a situation or experiment to the entire class. Course activities emphasize conceptual understanding and science process skills, i.e., having students learn how to ask questions, make predictions, gather evidence, and make inferences. The emphasis in the materials is on conceptual understanding and science process 
skills rather than on definitions of terms or theory and computations.

The course does not claim to be a methods course, but many aspects of the course instruction reflect a view toward the needs of future teachers and the development of pedagogical content knowledge. The instructors explicitly inform students that the inquiry-oriented classroom is designed as a model of the way in which K-8 teachers might teach science. The equipment used for most course activities is simple and readily available, and some former students have indicated that they have used similar activities in their own K-8 classrooms [25]. The hands-on nature of the course is intended to give students experience in using and troubleshooting simple equipment, as well as being mindful of safety procedures, particularly important in the chemistry portions of the course. As will become clear in subsequent sections, several course assessments are designed to cause students to reflect on their own learning. For example, the students are assigned a MERIT essay in which they examine the change in their thinking on particular course topics (the term MERIT is an acronym and will be described more fully in Sec. III C, below). The essay and accompanying peer review process are intended to stimulate thinking about the process of learning.

\section{B. Instructional materials}

At the time that this project was started, there was no existing inquiry-oriented course that encompassed both physics and chemistry topics. (Since that time, other materials have been developed that also satisfy this need [26].) As a result, a new course and text were developed locally. The text used for the course is Inquiry Into Physical Science: A Contextual Approach, by Nanes [27]. The text follows a lab manual format and questions guide students through making predictions, observations, and explanations. Narrative text is not designed to be all-inclusive as it might be in a traditional textbook but, rather, is intended to provide the background material necessary to be able to understand and interpret in-class activities. It is intended that the majority of student learning will take place in the activities, not by reading the text. In fact, many new ideas are encountered in the activities that are not explicitly discussed in the text itself. Activities are integrated into, and work in tandem with, the narrative text. In order to give a detailed view of how the activities are structured, a sample activity from the Underpinnings chapter entitled "Understanding Density" is reproduced in the Appendix. This is a two-part activity designed to help students to understand mass, volume, and density, and part II of the activity is examined in detail in Sec. VC as one of the research questions discussed later in this paper. A CD is available with ancillary instructor materials that include complete question-by-question discussion of all student activities as well as complete equipment lists, an exam question database, sample syllabi, schedules and other course-related materials.

As discussed above, a contextual approach is used to develop the course content. A separate volume of the book is devoted to each of the three content units (global warming, kitchen science, and the automobile), and a context or theme is established through a real-world problem or issue to provide a story line. The story line is established by a leading question that defines the broad scope of the content. The science concepts that are covered are those necessary to contemplate an answer to the leading question, but are also chosen to reflect the physical science content standards for preservice teachers in California. The three volumes of the book would be well suited for a full year course in physical science but few universities have that luxury, and the separate volumes can be used independently in the more typical one-semester course. At CSUF, the course typically covers selected activities from two of the three volumes each semester. One of those two has always been the Kitchen Science volume (where much of the chemistry resides), with Vol. 1 or Vol. 3 chosen depending on the instructors' preferences. If Vol. 1 is not included, students begin the semester with the introductory Underpinnings and Energy chapters from that volume, which are included as appendices to Vols. 2 and 3. A one-semester physics-only course could use Vols. 1 or 3 or a combination of activities from both volumes.

A brief discussion follows of the course content included in each of the volumes. A detailed table of contents for each volume is included in the Appendix. The content of the "Global Warming" unit (Vol. 1) focuses on the thermal equilibrium of the Earth and is built around the leading question: "Is global warming really occurring?" The first chapter of this volume, entitled Underpinnings, provides fundamental ideas that are important throughout much of the content in all three units such as density, graphical analysis skills, ratios, and proportional reasoning. As noted above, the unit examines energy, heat and temperature, and thermal equilibrium. The last chapter uses experiments with colored plastic filters to learn about light and color, and extends these ideas to spectral absorption as a basis for understanding the greenhouse effect. The chapter ends with three paper-and-pencil capstone activities that highlight some of the key issues in the global warming debate. These activities present numerous graphs of global historical temperature and $\mathrm{CO}_{2}$ data that aim to give students experience with interpreting graphical representation of data.

Volume 2, titled "Kitchen Science," includes much of the chemistry in the curriculum, with the leading question, "Will science be a guest at your next dinner?" After activities about the nature of matter, students consider atomic structure and the periodic table. Also, this volume revisits heat transfer, initially examined in Vol. 1, and students study how conduction, convection, and radiation provide different ways to cook foods. Chemical bonding 
and the shape of molecules are included in this volume as well. In the last chapter of the unit, students perform activities to discover properties of water including latent heats of fusion and vaporization and specific heat. This chapter also covers the chemistry of carbohydrates, fats and proteins.

Volume 3 is titled "The Automobile" and the leading question is, "Will the gas-driven automobile ever become a thing of the past?" Chapters 1 and 2 focus on onedimensional kinematics and dynamics, respectively, and end with impulse, momentum, and momentum conservation. The leading question comes into greatest focus in Chap. 3, Making Our Car Move, which examines various mechanisms for propulsion systems, from the internal combustion engine to electromagnetism to fuel cells. The chapter begins with activities to introduce students to combustion chemistry, heat of combustion, and the energy content of fuels. Students then study dc circuits, beginning with lighting a bulb, and then develop a model of electric current in a single bulb circuit before moving on to simple series and parallel circuits. Multiple battery circuits and the internal chemistry of batteries using electrochemical galvanic cells are the subject of some activities that follow. Finally, concluding experiments in which students study the compass needle galvanometer, dc motor, solenoid electromagnet, and electric generator inform about electromagnetism. In the final section of the unit, students perform paper-and-pencil activities covering air pollution, electric and hybrid vehicles, and fuel cells.

It is worth considering the ways in which the course curriculum contrasts with other research-based curricula for this population. In some ways, our course is more traditional, with more explanatory text accompanying the materials than is the case for comparable materials, and a coverage of larger number of topics, with the necessary corresponding decrease in depth. Physics by Inquiry [23], for example, is a very thorough and self-contained curriculum in which students build a deep understanding of target concepts almost entirely through their own experimentation and reasoning. Despite a deep admiration for this approach, we chose an alternative that is much less pure inquiry, in part due to state content requirements for courses for prospective teachers, which cover a much broader scope of material than Physics by Inquiry courses are typically able to do. Another comparable curriculum is Physical Science and Everyday Thinking (PSET) [26], which was developed after this course was already in place. In addition to the topic coverage, PSET differs from our course in its close adherence to a learning cycle and its explicit attention to themes of the nature of science and learning about learning.

\section{Course assessments}

Because the Phys/Chem 102 course has a different set of goals than more traditional courses, we have constructed course assessments in such a way as to measure and reinforce those goals. Student grades are based on course examinations, "Making Connections" homework assignments, MERIT essays, in-class performance tasks, and miscellaneous measures of class participation such as attendance and spot checks of activity sheets. Each of these assessments and the ways in which they complement course goals are discussed below. Specific examples of assessment instruments from each category are given in the Appendix.

Examinations.-To discourage any motivation to memorize content, all course examinations are given in an open book format - students are allowed to have their books, completed activities, and any additional notes that they may have taken during instructor presentations, whiteboard presentations, etc. Exams generally have two parts: explanatory multiple-choice and free-response questions. Multiple-choice questions always require that students provide an explanation for their choice, with a significant portion of the question score dependent on the quality of the explanation. Free-response questions require more detailed analysis and generally build upon the experiences that students had while doing in-class activities. These are often multipart questions that integrate target concepts that students are expected to have learned from the activities. An example of each question type is given in the Appendix.

Homework: Making Connections.-Homework assignments are called "Making Connections" and, as the name implies, are intended to make connections with previous activities and to provide additional exercises that reinforce and extend understanding of the current material. All of these exercises are provided in the text and examples are given in the Appendix.

MERIT essay.-The term "MERIT" essay is an acronym derived from the five goals of the assignment and is defined below in the following description taken directly from the course syllabus.

(1) Metacognition. A student who is metacognitive pays attention to the way they learn things. A MERIT essay should provide a brief commentary that traces and documents your learning of a new concept that you have learned in the laboratory. The essay is designed to force you to think about your own learning of a concept and how you learned it rather than demonstrating what you learned (which is the purpose of the other assessments in the course).

(2) Evidence. An important component of the MERIT essay will be to use scientific evidence from your own inclass work to document your learning.

(3) Reflection. The MERIT essay is intended to force you to go back over and reflect on what you have done to reach an enhanced understanding of your chosen topic.

(4) Inference. Making inferences from experimental data is essential to the learning process in science. The 
MERIT essay should describe how you reached conclusions from your experimental data.

(5) Transmission. It is one thing to think that you understand something, it is yet another to transmit that understanding to someone else in writing. The MERIT essay will encourage written expression of your learning.

Although the definitions of "metacognition" and "reflection" may seem to overlap, our intention was to make connection between the five parts of the MERIT acronym and the five main categories for the assessment rubric. (See the Appendix.) In this scheme, what we label as metacognition is intended to focus on the student thinking itself, and what we label as reflection is intended to focus on what activities and exercises the students did ("what you have done") that might influence that thinking. Since that initial articulation of the assignment, we have added the peer review process, which typically provides students with an opportunity to reflect in a different way, by considering the learning pathway described by a peer.

The MERIT essay is a maximum of two typewritten pages, in which a student describes their learning pathway for a self-selected topic chosen from several instructordefined topics. The development of this assignment was strongly influenced by the "Learning Commentary" assignment used by Fred Goldberg at San Diego State University. Students are asked to identify which activities helped to change their understanding and to specifically identify the questions and tasks in those activities and describe how the sequence of those activities and questions were key to their learning. This aspect of the essay is specifically intended to have students think about the relationship between their observations, written responses, and class discussions, and the ways in which these influence the development and modification of their models of the physical world. Students are required to attach to the essay copies of their work from the relevant activities, pretests and posttests, Making Connections assignments, and exams that document and trace the evolving changes in their thinking about the newly learned concept.

This assignment proves to be very difficult for students - they are more accustomed to trying to prove to the instructor what they have learned on an exam or in a descriptive term paper rather than performing a selfevaluation of how they have learned it. To help understand the focus of the essay, students are given at the outset a copy of an actual MERIT essay that had been turned in by a prior student, annotated with suggestions as to what the student might have done to make the essay more consistent with the goals of the assignment. A copy of an annotated essay is included in the Appendix, and, it is noted that this essay relates to the density activity that is reproduced in the Appendix.

The MERIT essay assignment includes three phases over an approximately three-week period-a first draft, a peer review, and a final draft. Students are given a week to write a first draft of their essay. This draft is then given anonymously to a classmate to review. At the time that they are given an essay to evaluate, students are given a list of criteria and a rubric (see the Appendix) that the instructor will use to assess the final draft of the essay when it is turned in. Using these criteria, the student takes one week to review their classmate's essay, to make comments and suggestions, and to assign what they would give as a grade for the assignment. This is a useful exercise for students who will be future teachers. This peer review is then returned to the original author and the instructor retains a copy of the peer review. Students then have an additional week to evaluate the comments made by the peer reviewer and choose the extent to which they wish to revise their essay. The revised essay is then submitted in final form to be graded by the instructor, using the same criteria and rubric used by the students in the peer review process.

In doing their peer review, students are instructed to make a careful and honest appraisal of their classmate's essay, but are told that the grade they assign their peer will not figure into the essay author's grade. The effort and care taken by the student in doing the peer review, as gauged by the instructor review of the retained copy of the peer-reviewed essay, does, however, affect the reviewer's MERIT grade. A student who merely identifies typographical and spelling errors will not score as high on the review component of the grade as a student who makes a serious effort to identify departures from the goals of the essay and makes serious efforts at suggesting improvements. Retaining the peerreviewed essay also enables the instructor to note how serious an effort the essay author makes to evaluate and incorporate the suggestions made by the peer reviewer.

Performance tasks.-Performance tasks are an attempt at authentic assessment rather than paper-and-pencil tasks. As an example, the following task is given to students after they have completed studies of electric current and electric circuits. At this point in the course, students should understand that the intensity with which a bulb lights is a measure of the amount of electric current through the bulb. They have studied series and parallel circuits and are expected to understand that bulbs in series reduce and bulbs in parallel increase the total current drawn from the battery. Students are also familiar with a series battery and bulb combination configured as a "circuit tester" with test leads and its use to test for open, closed, and short circuits. This activity expects students to extend their thinking and use the brightness of the bulb in the circuit tester as a way to compare the current in several "mystery" circuits and to use this information to identify the circuits. The detailed instructions given to students to perform the task is given in the Appendix.

Another performance task requires students to determine the temperature of a sample of very hot water using a thermometer that has a scale with a maximum temperature of $50{ }^{\circ} \mathrm{C}$. Students are required to first write 
down their plan and then execute the plan to determine the water temperature based on their prior experience in analyzing mixtures of hot and cold water. Since heat loss is a major source of error, students are not graded on the accuracy of their results. Rather, they are assessed based on the feasibility, simplicity, and uniqueness of their devised procedure, clarity of their written description, care in recording data, and their calculations and data analysis used to obtain their results. After completion of the task, in an instructor-led discussion, students are told the actual temperature of the hot water. The large difference between their measured temperature and the actual temperature allows for a discussion of the error introduced by heat loss and how it could have been minimized.

Class participation.-A small portion of a student's grade is based on attendance and on spot checks of the activity worksheets that students complete as they work through experiments in class. Although these activity sheets are not graded, they are periodically collected and reviewed for completeness. Students are thus encouraged not to leave questions unanswered as they work through the activities. Each individual activity in a batch of completed worksheets is given a small point allocation that is weighted with the attendance into the student's grade.

Grading.-All of the primary assessment instruments discussed above require the evaluation of written responses from students. Needless to say, this type of assessment is much more time-consuming than merely testing students with rapid response "short answer" types of questions. As noted above, each section of the course has a cap of 26 students, a number that makes assessment manageable for the grading tasks such as exams, performance tasks, and MERIT essay that occur relatively infrequently during the semester. Exams are constructed to have, typically, approximately three to five multiple-choice questions (each requiring a short written explanation of the chosen answer) and three or four multipart questions, with each part requiring a short free response. Experience has been that careful grading of 26 exam papers of this type might take about 10-12 hours. This is comparable to the time that would likely be required to grade four or five computational problems on a traditional physics exam where careful review is necessary to give students "partial credit" for their solutions. Performance tasks can be graded relatively quickly (1-2 hours for the entire class) because of a narrow focus on a single outcome from the students' in-class measurements. Because of the subjective nature of the MERIT essay, careful grading of a class set of essays can be very time-consuming, taking perhaps $15-20$ hours. The strict requirement of a maximum length of two pages helps to keep the reading time manageable, but the most difficult aspect of grading the MERIT essays is maintaining consistency and adhering to the grading rubric provided to the students. This is addressed further below. The heaviest grading burden arising from the different assessments used in the course arises from the "Making Connections" homework assignments that students are required to turn in every 1-2 weeks. As for any physics course, if an instructor wants to include homework as part of the total course assessment, self-grading these regular assignments could require a prohibitive effort unless grading assistance is available. As discussed below (Sec. IVA), we have been fortunate so far to receive financial support for "peer assistants" in each section to grade homework assignments with the help of detailed answer keys and explanations provided in the instructor materials for the text. In many cases we have sample rubrics indicating how much credit should be assigned for common incorrect or incomplete answers. Our use of grading assistance has been only to grade homework-exams, performance tasks, and MERIT essays have always been graded by the instructor.

In addition to the labor-intensive aspect of the assessment instruments used in a course like Phys/Chem 102, one must be concerned with students' view of consistency and fairness in grading. As with all assessment procedures, transparency is crucial to develop trust in the grading process. Returning graded work in a timely way, indicating clearly the reason for assigned scores, and encouraging students to clarify questions about graded work in class or in office hours all help to develop trust. For the MERIT essay, which is more subjective than other assessment instruments, a sense of fairness is greatly facilitated by the way the assignment is administered. The fact that the students have the grading rubric in advance so that they are very clear about the grading criteria, the fact that they receive a sample essay that is annotated to help understand the nature of the assignment, and the fact that they receive feedback from a peer and are given the opportunity to make changes if they choose to all enhance student perception of fair assessment. In assessing the MERIT essay another strategy that enables the instructor to feel that the grades are reasonable while at the same time contributing to student perception of fairness is to read through all the essays while annotating with comments that are aligned with the rubric before putting point scores on any paper. Then, on a second pass, one can divide the papers into groups that fulfilled the goals of the assignment from best to worst and grades can then be recorded. Of course, the second pass takes much less time than the first because written comments are already on the paper, but this approach obviously adds to the time burden of assessing the MERIT essays. However, with all of the above considerations, we have not had student complaints about fair grading.

\section{QUALITATIVE AND PROGRAMMATIC MEASURES TO ASSESS THE COURSE}

In a subsequent section we will describe research questions that we have posed in the context of Phys/Chem 102. 
First, however, we will describe qualitative and programmatic measures of the success of the course and describe ongoing challenges.

\section{A. Measures of success}

The course is locally perceived to be a strong success and has achieved a number of important benchmarks: dissemination of course materials, increased enrollments, and acceptance by faculty in the College of Education. The course materials have been tested or adopted by several other institutions and are currently in use at three: Cal Poly Pomona, Santa Ana College, and Santiago Canyon College [28].

An important measure of success in the CSU system is enrollment, as revenues follow students. Student demand for the course has been strong, and the course has grown from only one 26-student section in Spring 1999 to four sections serving approximately 100 students per semester, until budget constraints as described below. Phys/Chem 102 has become institutionalized as one of the courses that satisfy the lower-division requirements for a Natural Science minor.

Our colleagues in the College of Education have received the course enthusiastically, seeing the course pedagogy as the preferred way to teach science content to future teachers. It is one of the required courses for students in the Streamlined Teacher Education Program (STEP), an integrated teacher education program that allows students to simultaneously earn a bachelor's degree and the preliminary teaching credential within 135 units (compared to the usual 120 units for a bachelor's degree plus 35 or more units for the preliminary teaching credential). As with the inclusion in the Natural Science minor, the STEP requirement bodes well for the continuing existence of the course.

The support from local sources has extended to significant financial commitments. The CSUF department of Chemistry and Biochemistry renovated an existing laboratory classroom to suit the instructional methods of Phys/ Chem 102, and this room is now dedicated exclusively to the course. The course has received approximately $\$ 21000$ in support from a variety of intramural sources to purchase equipment and supplies. In particular, the College of Education allocated $\$ 10000$ from a Stuart Foundation grant to purchase notebook computers used for data acquisition in some of the experiments done in the classroom.

After the first year of Phys/Chem 102, a Peer Instructor program was created, with initial support coming from the Stuart grant in the College of Education. Each semester high performing students in Phys/Chem 102 were selected and hired to be peer instructors for the course the following semester. These students attended class on a regular basis as teaching assistants, interacting with students as they worked in their collaborative groups and also helping with administrative and logistical tasks including equipment setup. In contrast to a more formal Learning Assistant model, the training for these peer instructors was typically limited to a weekly meeting with course faculty focusing on course content and suggested instructional strategies [29]. This experience has proven to be extremely beneficial to the participating students, who improve their own understanding of the course material and have a chance to practice their teaching skills. Further, these students serve as useful role models and resources for students who are taking the course for the first time. Often students find the perspective of a peer who has recently learned material to be a useful supplement to that of more experienced instructors.

The Departments of Physics and Chemistry and Biochemistry continued to share support for the Peer Instructor program for two more years after the expiration of the Stuart grant. In 2005, we secured grant funding from the Boeing Corporation, which has totaled $\$ 47000$ over three years. This grant funded the purchase of additional equipment and supplies as well as the continuation of the peer instructor program.

The peer instructor program has attracted a number of strong students and influenced some of them to change their career goals. For example, one student who served as a peer instructor for several semesters graduated and is now a full-time fifth grade teacher. She completed the Master of Arts in Teaching Science (MAT-S) degree at CSUF in part in order to be able to teach an evening section of the 102 course as a part-time instructor.

\section{B. Challenges}

While the course has largely been successful, there have been a number of challenges, some ongoing, that in some cases threaten the very existence of the course. The most significant issue is the cost of the course. Compared to the large lecture format, the small-group collaborative pedagogy makes the course very labor intensive and very expensive to run. As already noted, California has entered another cycle of budget cuts, and the cost of the course has made it a target for cuts.

Staffing the course can be difficult. Many full-time faculty are unwilling or unable to teach the course because they are not comfortable with the inquiry-based pedagogy. In addition, the joint nature of the course can be problematic for potential instructors. Though the content is relatively elementary, some instructors are not comfortable outside their own discipline: chemists are not used to teaching about electric circuits and physicists are not used to using glassware and teaching about chemical reactions. In some cases, assignment of part-time faculty has led to compromising pedagogical issues and the continuity of student experience.

Another staffing difficulty is related to student ratings of instruction. Some faculty in the course have found that average scores on student evaluations are lower than for other lower-division courses. Students are often 
unreceptive to the science content to start with and are not comfortable having to take a greater responsibility for their own learning. Strategies such as passive listening in a lecture, memorization, and reading and underlining in a textbook that may work in a traditional lecture class do not work well in this course. Students often express this dissatisfaction by saying: "I do not like it when the instructor answers a question with another question." This type of student response is similar to that reported in the literature on reform efforts in science education [30]. Halpern and Hakel [31] reported that, although active learning strategies may result in significantly greater learning gains, the learning tasks may take longer and require greater student effort, may be less enjoyable for the student, and may lead to lower student ratings of their instructor. At CSUF, the retention, tenure, and promotion process for faculty relies heavily on student ratings of instruction, making Phys/ Chem 102 a potentially risky teaching assignment for untenured faculty. Even experienced instructors may have a steep learning curve to adapt to the pedagogical demands of guided inquiry and some have experienced more student dissatisfaction than in comparable traditional courses.

\section{RESEARCH QUESTIONS}

As we have taught the course, we have sought to examine several aspects of the course in terms of physics and chemical education research. Data on students in the course have been presented as part of numerous presentations and papers. For the purpose of this paper, we will describe a subset of the research that we have conducted, with a view to research questions whose results will inform instructors and departments that are considering developing or adopting courses of this nature.

The primary research questions that we consider in the paper are as follows.

To what extent have prospective teachers entering university science courses mastered the K-8 California physical science standards that they will be expected to teach?

To what extent does student understanding of science content change as a result of instruction in this format?

How does the initial level of understanding for prospective teachers in this course compare to those in more traditionally taught physical science courses serving broader student populations?

In the sections below we will examine data bearing on these questions. While we have not performed strictly controlled experimental studies of student learning, we have gathered data on pretest and posttest instruments in this course and, where possible, given matched questions in Phys/Chem 102 and the comparable general education courses offered in physics and chemistry. A colleague has collected data on student responses to pretest and posttest questions while using this curriculum at another university [28]. Those data show conceptual gains in six different content areas and are broadly consistent with those that we report below.

In several of the examples below, we show comparison data from a CSUF general education physics course taught at a similar level. This course, which we describe as "Survey of Physics" or "the survey course," is a fairly typical lecture course intended for a general education audience. Particularly important is to note that this course is often taken by prospective teachers instead of Phys/ Chem 102 [8]. The course includes 3 hours per week of lecture instruction with either two or three weekly meetings. Currently there are two sections each semester of 70-90 students each. The course text is a locally produced set of lecture notes produced by R. Nanes, so it shares some influences with Phys/Chem 102 as well as the Conceptual Physics courses common for such a course level [32]. The course emphasizes conceptual understanding and covers much of the same material as the physics portion of Phys/ Chem 102: underpinnings, energy, heat and temperature, global warming, kinematics and dynamics, and electricity and magnetism. The survey course does not require calculus or high school physics, and the most difficult mathematics used is ratio reasoning or very simple algebra. The majors of students taking this course span the university, though there are very few science, math, or engineering majors. Approximately a third of the students take a corresponding lab course.

The corresponding general education course offered in the Department of Chemistry and Biochemistry is also a survey course. There are usually two to three sections of the course taught each semester in a traditional lecture format for 60-100 students three hours per week in two or three weekly class sessions. The pedagogy for survey chemistry is fairly traditional and the preparation of prospective K-8 science teachers is not necessarily a factor in its curriculum. Prerequisites for the survey chemistry course are the equivalent of high school algebra and high school science required for admission to the university. The survey chemistry course does not fulfill requirements in chemistry for science majors; thus, most of the students are nonscience majors from across the university. A corresponding lab course fulfills the general education laboratory requirement, but its curriculum is not linked to the survey lecture course.

\section{A. Example: Entering students' understanding of mass, volume, and density}

As we teach the various content areas in the course, we make an effort to document the initial level of student understanding, particularly of those topics from the California science standards that prospective teachers are likely to teach in their future classrooms. As an example, we present a small selection of sample data from questions on mass, volume, and density that we pose on an ungraded pretest given on the first day of class, as students begin 


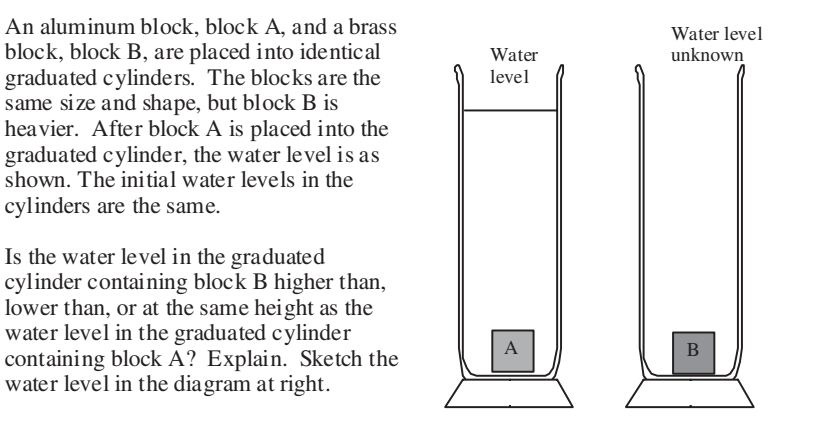

FIG. 1. Water displacement problem posed before instruction on an ungraded quiz in Phys/Chem 102 as well as a comparison course.

their study of the Underpinnings section. This pretest comes before any instruction in Phys/Chem 102, so it reflects the incoming knowledge of students. The California Science Standards require that students in grade 4 understand how to measure volume, and that students in grade 8 understand density and its relationship to sinking and floating behavior, so any high school graduate would certainly be expected to know this material [33].

The question illustrated in Fig. 1 is the first part of the ungraded pretest. Students are asked to compare the volume of water displaced by two blocks of the same size and shape but different mass. In order to avoid potentially memorized responses, the question is not phrased in terms of displaced liquid, but rather asks students to sketch the water surface in a container. The results on the water displacement problem are shown in Table I and are roughly consistent with those from previous studies [34]. A little more than half of the students answer correctly, with a large fraction of the students stating that the heavier block will cause a greater change in the water level. We also see a significant edge in performance among the students in the Survey of Physics course, which will be discussed in Sec. V D below.

Another portion of the first pretest is shown in Fig. 2. In this question, adapted from a similar problem on electric charge density, a solid block of plastic is cut into two smaller pieces [35]. Students are asked to compare the masses of the original block and the two parts, then to

TABLE I. Student responses to the water displacement problem (Fig. 1).

\begin{tabular}{lcc}
\hline \hline & $\begin{array}{c}\text { Phys/Chem 102 } \\
\text { CSUF } \\
9 \text { sections }\end{array}$ & $\begin{array}{c}\text { Survey of Physics } \\
\text { CSUF } \\
\text { 3 sections } \\
N=222\end{array}$ \\
& $56 \%$ & $72 \%$ \\
\hline Same water levels (correct) & $39 \%$ & $21 \%$ \\
$\begin{array}{l}\text { Heavier block displaces } \\
\text { more liquid }\end{array}$ & $5 \%$ & $7 \%$ \\
Other incorrect or blank & & \\
\hline \hline
\end{tabular}

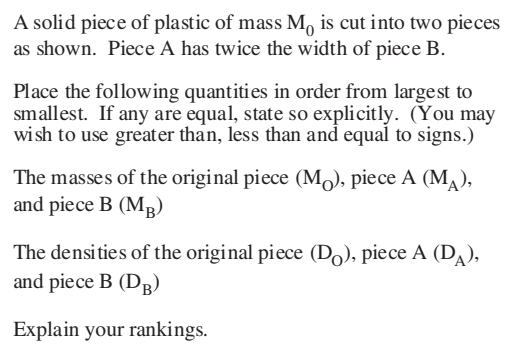

FIG. 2. "Broken-block" density problem posed before instruction on an ungraded quiz in Phys/Chem 102.

compare the densities of the three pieces. Students are expected to recognize that density is the ratio of mass to volume, and a characteristic property of materials, so that the three pieces will all have the same density.

As shown in Table II, the broken-block problem in Fig. 2 is quite challenging for students. Only approximately a third answer correctly. The largest group of students give answers in which the larger pieces have larger densities (i.e., $D_{0}>D_{A}>D_{B}$ ). The explanations given by students in this category typically refer to the size of the object: " $D_{0}$ is the most dense because it is the largest piece." A significant fraction of the students give exactly the opposite answer, in which smaller blocks have a greater density. A sample student response reads, " $D_{B}$ is more dense than $D_{A}$ because it is smaller in size and thus weighs less as well." In addition, a number of the explanations supporting correct answers were incomplete or incorrect, seemingly reflecting a failure to recognize the definition of density as the ratio of mass to volume: " $D_{0}=D_{A}=D_{B}$. The size does not change the density. It is the weight that changes it."

After the pretests, students complete several in-class activities on mass, volume, and density. (See the Appendix.) Students perform an activity that is essentially identical to the water displacement question in Fig. 1. In most semesters, we give additional ungraded quizzes after instruction including the questions from Figs. 1 and 2, to help students to document the progression of their understanding for the MERIT essay. After seeing a demonstration and observing the water displaced by two metal bars of the same volume but different mass, approximately $100 \%$ of the students answer the water displacement question

TABLE II. Student responses to the broken-block density problem (Fig. 2).

\begin{tabular}{lc}
\hline \hline & $\begin{array}{c}\text { Phys/Chem 102 } \\
9 \text { sections } \\
(N=222)\end{array}$ \\
\hline All densities equal (correct) & $30 \%$ \\
Larger piece has greater density & $54 \%$ \\
Smaller piece has greater density & $12 \%$ \\
\hline \hline
\end{tabular}


correctly. That is reassuring, but the demonstration is essentially the same physical situation as the pretest and posttest. The activity on density is not as closely related to the pretest question in Fig. 2. Students measure mass and volume for several objects constructed from a set of plastic cubes and measure masses and volumes for various samples of the same liquid, finding in each case that the ratio is very similar for samples of a given material. Shortly after completing these activities, approximately $80 \%$ of students answer the density question in Fig. 2 correctly.

In addition, we have posed a number of multiple-choice and free-response questions testing these concepts on course examinations, after students have completed homework on this material and used the idea of density in later activities. In several exam questions, students were asked to compare the density of a small chip removed from an object to the density of the larger object from which the chip was removed. In others, this concept was extended to the sinking and floating behavior of the objects. For example, see the multiple-choice question in the Appendix. Student performance on these questions in course examinations suggests very strongly that student understanding has improved. For example, on several different densityonly questions posed over the course of three sections $(N=78), 94 \%$ of students answered correctly that the densities of a small piece and the larger body would be the same. Given the improvement over the success rate on the pretest, these data indicate that the Phys/Chem 102 course has a positive impact on student understanding of this topic. On the more involved questions involving sinking and floating $(N=54), 74 \%$ of students answered correctly that the larger and smaller objects would behave in the same way. Although we have not asked this sinking and floating question directly on a pretest, results in the next section illustrate that the connection between density and sinking and floating were quite difficult for students before the corresponding activities, with pretest success rates of under $35 \%$.

\section{B. Example: Student understanding of sinking and floating}

In this section we refer to a study of student understanding of sinking and floating, described in greater detail elsewhere [36]. On a written pretest, students are asked a series of questions about a small sealed bottle containing pieces of metal shot. The pretest begins by asking students to consider a situation in which the bottle floats in a beaker of water. They are then asked to predict what would happen if a piece of metal were removed and the bottle were returned to the water. The problem continues with the question shown in Fig. 3, which we describe as the Shot problem. These questions were posed in Phys/Chem 102 as well as the Survey of Physics course, again at a point in the course before any explicit classroom instruction on the topic of sinking and floating (but after the instruction on

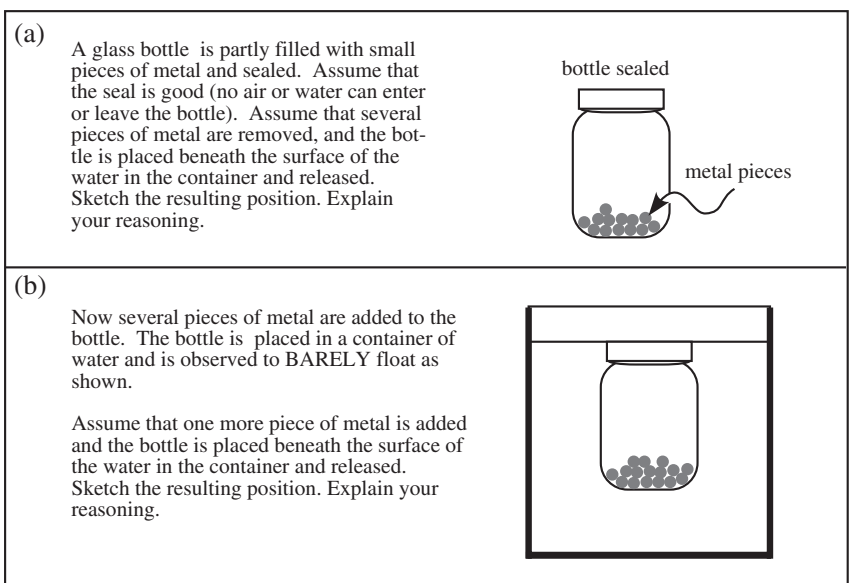

FIG. 3. The Shot problem. Panel (a) gives the initial setup and a preliminary question. Panel (b) is the part referred to in the text and data tables. This problem is given on an ungraded quiz in Phys/Chem 102 and a comparison course after instruction on density but before instruction on sinking and floating. This task is also now used as an instructional activity.

density described above). Results from the second part of Shot problem [Fig. 3(b)] are shown in Table III.

In contrast to most of the examples in this paper, student performance in Phys/Chem 102 and the survey course was very similar, with about a third of the students in each class answering correctly and about half giving the same common incorrect answer.

After some initial research, the curriculum for the Underpinnings section of Phys/Chem 102 was altered to include an activity based on the Shot task (see part 2 of activity 1.6.1 in the Appendix). First, the students examine the bottle filled with shot as it barely floats and predict how the system would behave in the water after a single piece of metal was removed. After discussion the instructor performs the demonstration. Very few students are surprised by this result. Then the students are asked to consider the question in the written version of the task. They predict the behavior of the system after one additional piece of shot is added, and then discuss their prediction with peers. As indicated in the pretest results, many students predict that the bottle will float just below the surface of the water. The instructor then performs this demonstration. If the initial

TABLE III. Student responses to the second part of the Shot problem [Fig. 3(b)] in Phys/Chem 102 and Survey of Physics.

\begin{tabular}{lcc}
\hline \hline & $\begin{array}{c}\text { Phys/Chem 102 } \\
12 \text { sections } \\
N=316\end{array}$ & $\begin{array}{c}\text { Survey of Physics } \\
4 \text { sections } \\
N=177\end{array}$ \\
\hline Sink to bottom (correct) & $33 \%$ & $35 \%$ \\
Float below surface & $53 \%$ & $49 \%$ \\
Other (e.g., make no & $14 \%$ & $16 \%$ \\
difference) & & \\
\hline \hline
\end{tabular}




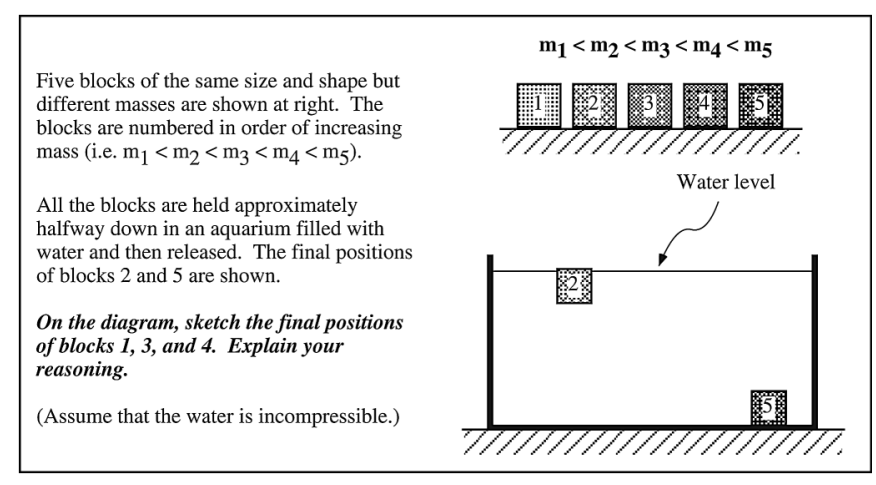

FIG. 4. The Five Blocks problem.

state of the system is indeed just barely floating, the addition of even a small piece of paper is enough to make the bottle sink to the bottom. This outcome is typically surprising for many students and provokes a rich and thoughtful discussion.

As a posttest for this activity, we have posed the Five Blocks problem (Fig. 4) developed in previous studies [37]. As students have not seen this problem before, we feel it is a more rigorous test of student understanding than a repeated administration of the Shot task. Results are shown in Table IV. Before the revision of the activity on sinking and floating, the Phys/Chem 102 course included a handson lab activity on sinking and floating including a Cartesian diver demonstration. In these sections of the course, only about $15 \%$ of the students answered the Five Blocks question correctly after all instruction on density and sinking and floating. In the unmodified lecture-based Survey of Physics course, the success rate is somewhat greater, but still low. In sections of Phys/Chem 102 completing a revised activity including the Shot task, success on the Five Blocks question after instruction was over $70 \%$. For completeness, we include data from sections of the Survey course using a lecture demonstration version of the Shot activity. This activity was similar in structure to the activity in Phys/Chem 102, with the cycle of prediction, observation, discussion, but did not include written worksheets for students to record predictions and explanations; the success rate on the Five Blocks question in these sections was also high but a bit below that of Phys/Chem 102.

The results on these problems provide a strong signal that the instructional strategies used in Phys/Chem 102 can help to improve student learning as compared to traditional lecture instruction, as students would encounter in the Survey of Physics course. However, they also suggest that hands-on activities by themselves do not necessarily improve student learning; the sections of Phys/Chem 102 using the early version of the density activity showed results that were less successful than the traditional course. Thus we believe that the details of the activities in a course of this type are crucial and often require an iterative development cycle including repeated classroom tests, assessment, and revision of the materials [38].

\section{Example: Student understanding of physical and chemical changes}

State science standards for fifth grade include the idea that chemical reactions require that atoms rearrange to form substances with different properties [39]. As part of ongoing research into student understanding of physical and chemical changes, students in six sections of Phys/ Chem $102(N=157)$ were given an ungraded ten-question survey, the Physical-Chemical Change Assessment (PCA), during the first few weeks of the course. The PCA includes a variety of representations of substances undergoing changes, including text, chemical symbols, and macrosopic and particulate-level illustrations (see sample items using each of these four representations in the Appendix). Entering students had an average success rate of $67 \%$ prior to instruction, again suggesting deficiencies in the entering content preparation of students. The questions involving the particulate-level representations were the most difficult for students, with a success rate of $62 \%$.

Physical and chemical change is a topic that is specifically addressed in an activity in the Kitchen Science volume of the Phys/Chem 102 curriculum. In order to measure the extent of student learning of this topic, the PCA was administered again at the end of the semester. Student performance was significantly better, with an average success rate of $79 \%$, including $76 \%$ correct responses for the problems involving particulate representations [40].

\section{Comparison of student population to general education science courses}

As noted above, if Phys/Chem 102 were not available, preservice teachers would likely end up taking more traditional lecture-based courses to satisfy their science

TABLE IV. Percentages of students giving correct answers on the Five Blocks problem after all instruction on density and its connection to sinking and floating, for different course types and instructional interventions. Each row in the table below except the first includes at least two different instructors.

\begin{tabular}{|c|c|c|c|}
\hline Phys/Chem 102 (4 sections) & Hands-on lab-based including Cartesian diver & $15 \%$ & $N=94$ \\
\hline Phys/Chem 102 (12 sections) & Shot demonstration with worksheet & $71 \%$ & $N=316$ \\
\hline Survey of Physics (2 sections) & Standard lecture & $36 \%$ & $N=121$ \\
\hline Survey of Physics (6 sections) & Shot demonstration without worksheet & $65 \%$ & $N=280$ \\
\hline
\end{tabular}


TABLE V. Comparison of fractions of students giving correct responses on a variety of common problems in Phys/Chem 102 and the corresponding survey courses in physics and chemistry at CSUF. The problems in all cases were posed at similar points in instruction, typically after reading and brief introductory lecture but before any research-based instruction.

\begin{tabular}{lcc}
\hline \hline & Phys/Chem 102 & Survey of Physics \\
\hline Pendulum questions & $N=48$ (two sections) & $N=53$ (one section) \\
Kinetic energy comparison & $58 \%$ & $87 \%$ \\
Grav. potential energy comparison & $54 \%$ & $92 \%$ \\
Total energy conservation & $50 \%$ & $71 \%$ \\
Heat \& temperature questions & $N=51$ (two sections) & $N=57$ (one section) \\
Temperature prediction & $84 \%$ & $88 \%$ \\
Heat lost = heat gained & $25 \%$ & $43 \%$ \\
& Phys/Chem 102 \\
Particulate representations & $N=22$ (one section) & $N=110$ (one section) \\
Solid & $27 \%$ & $50 \%$ \\
Gas & $27 \%$ & $49 \%$ \\
\hline \hline
\end{tabular}

requirements. We have performed some research to compare the initial content understanding of the student populations in the two course types. Our intent here is twofold. First, we wish to characterize the level of science understanding in the two groups, to get a sense of how the preservice teachers compare to a broader audience of college students at a given institution. Second, we hope to gauge the extent to which preservice teachers would be in a position to "compete" with the student population in the more traditional courses.

We have given a handful of pretests in Phys/Chem 102 that are matched with pretests given in the corresponding survey course in physics or chemistry. In each case, the pretests were given at similar points in instruction. In the first two cases described in this section, students had been assigned reading on the subject matter of the pretests, but had not begun formal instruction, so in practice the pretests are essentially measuring the incoming level of student understanding. In the third example, the questions were posed prior to instruction. As in the more in-depth examples in the two previous sections, the questions chosen are quite simple by most standards, reflecting the level of material that might be covered in precollege science courses. Each item tests material included in the state content standards for precollege science, as well as those for preservice teachers [41]. Here we show data from three additional examples of content questions that are representative.

The first example involves pretest questions on potential and kinetic energy in the context of a pendulum [42]. These questions were common to Phys/Chem 102 and Survey of Physics, and required fairly straightforward comparisons involving the application of the definitions of kinetic energy and gravitational potential energy, plus the energy conservation law. (See the Appendix for all research questions referenced in this section.) In both cases, students had been assigned reading on the material, but the pretest would largely reflect prior knowledge. As shown in Table V, in each of the questions, the students in the survey course were fairly successful in answering correctly, but those in Phys/Chem 102 had more difficulty.

A second example is drawn from heat and temperature, a topic addressed in both courses. Students were given a pretest with several questions involving straightforward predictions in the context of a mixture of a sample of cold water with a sample of hot water of twice the mass. Students were asked to predict the final temperature of a water mixture and to state whether the heat lost by the hot water in the process was greater than, less than, or equal to that lost by the cold water. While most students are able to predict that the final temperature will be closer to the hot water temperature, most students have difficulty with the heat transfer question.

A third example is drawn from chemistry and involves particulate models of matter. Students were shown a macroscopic illustration of a substance and asked to draw a particulate-level representation of the substance (see Fig. 5). Students should identify from the given chemical

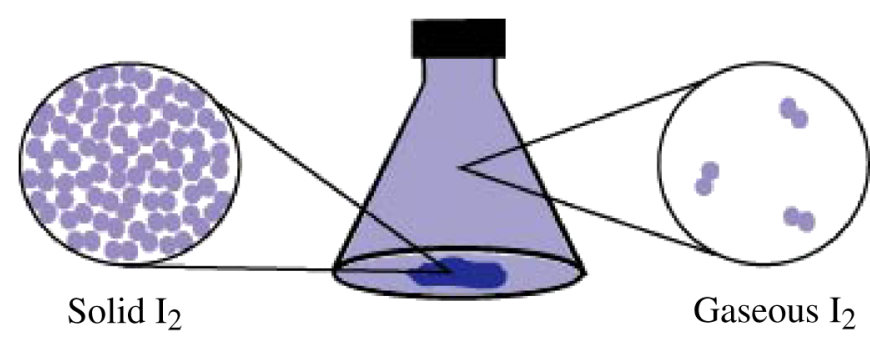

FIG. 5 (color online). Students are asked to draw particulatelevel representations of solid and gaseous $I_{2}$ (iodine). One potentially correct answer is shown. 
formula the diatomic nature of iodine as an element. This is depicted as a symbol for an iodine atom connected to another identical symbol. The molecules of iodine as a gas would be depicted as separate from one another and filling all of the available space in the box. The solid molecules will be shown in the box as aggregated (localized). Both groups struggled with this problem, but the survey chemistry students were approximately twice as likely to draw an appropriate particulate-level illustration of a solid or gas as the students in Phys/Chem 102.

These data and those in the previous sections indicate that even fairly straightforward physical science content is not well understood by a healthy fraction of the students entering Phys/Chem 102. From reports of colleagues using the course materials at other institutions, we feel comfortable in claiming that this phenomenon is not restricted to CSUF. Although these questions cover material that is normally taught in precollege science courses, and is covered in K-12 science standards, a large fraction of the students did not display a deep understanding, and it seems clear that these students would face challenges when teaching this material.

In most of the cases in this paper, we see better performance among students in the survey courses than in Phys/ Chem 102. This apparent edge is consistent with our subjective impression that the survey course students on average have stronger science and mathematics backgrounds. It may also reflect self-selection. For example, students in the Survey of Physics course have chosen to take physics as opposed to other GE offerings, often because of their interest in physics and/or a strong high school physics background. In contrast, most Phys/Chem 102 students do not have the same latitude in course selection.

While the trend on these problems is strikingly consistent, we do note that there are other problems on which both groups of students do very poorly. For example, on pretest questions involving subtractive color, the success rate for students in Phys/Chem 102 and the survey course was essentially $0 \%$. Similarly, on questions involving particulate representations of a chemical reaction with a limiting reagent, the success rates in Phys/Chem 102 and the survey chemistry course are between $10 \%$ and $15 \%$, with a slight edge for the survey course.

The difference in performance only reinforces the need for special courses. Many previous studies have shown that traditional physics lecture courses do not produce deep understanding of physics content or the nature of science. Our data suggest that if the prospective teachers in Phys/ Chem 102 were in a more traditional course, many of them would be relatively poorly prepared compared to their peers, in an environment that would neither encourage deep learning nor provide opportunities to reflect on one's understanding. It is very unlikely that this combination of factors would result in preparing teachers to teach physical science effectively.

\section{CONCLUSION}

The development and implementation of Phys/Chem 102 at CSUF required a multiple year commitment on the part of several faculty. The course is viewed as a success locally and has become institutionalized. While several outside funding sources were instrumental in the conception and initial development of the course, the course continues even without this external funding. The initial development process was an exemplar of interdisciplinary cooperation, including not only the two departments directly involved in the course but also our colleagues in the College of Education. We are particularly proud of the Peer Instructor program and the reports we have of its influence on the students participating in the program.

Despite these achievements, there have been challenges along the way, and the continuing success of the course may be threatened, as its special character requires small enrollments and the ongoing collaboration of two academic departments with distinct characters and financial constraints. Staffing of the course has often been a challenge for the two departments involved. As of Fall 2009, local budgetary concerns have led to the cancellation of multiple sections of the course, and there is no guarantee that these sections will be reinstated. Because of the enrollment cap required by the lab classroom and the pedagogy, a course like Phys/Chem 102 is relatively expensive to operate, and our experience suggests that such a course will always be a potential target when budgets are tight.

We have performed some research on several aspects of the course. Our work suggests that the students entering Phys/Chem 102 often have significant difficulty with material that is covered on state science standards, including relatively basic material like mass, volume, and density that they will be expected to teach in K-8 classrooms. The students in this course seem to have even less preparation in physical science on average than the typical nonscience majors in large lecture survey courses intended to satisfy general education requirements. We believe that special courses like Phys/Chem 102 are particularly important for those students who have relatively weak science backgrounds. These students would likely be among the weaker students in a large survey lecture course, and in such a course they would have little opportunity to reflect upon their learning or discuss the content with other students.

Our results suggest that the instructional strategies in Phys/Chem 102 course do have some successful impact on student learning. Student performance on density questions improves dramatically, for example. However, our work on sinking and floating suggests that the details of the activities are very important. Early versions of activities failed to have the desired impact on student learning, despite the fact that students were in a small-group setting doing activities focusing on conceptual understanding, and only 
after the activities were revised based on research did student performance improve to the desired levels. In the cases described above, an iterative approach to course development informed by research on student learning has led to significant improvements, but such an effort is quite intensive and time-consuming, and well beyond the typical expectations of course instructors.

In conclusion, we believe that we have learned a great deal from the experience of developing, implementing, and assessing Phys/Chem 102. This course is relatively unusual as an example of continuing interdepartmental collaboration that appears to be sustainable. We are hopeful that our description of these experiences and selected research findings can be of use to colleagues at other institutions.

\section{APPENDIX: EXAMPLES OF THE INQUIRY-BASED COURSE}

See separate auxiliary material for the assessment, MERIT essay, performance task, curriculum sample, interactive demonstration, research problems, and Table of Contents for the Inquiry into Physical Science.
[1] See, for example, L.C. McDermott, A perspective on teacher preparation in physics and other sciences: The need for special courses for teachers, Am. J. Phys. 58, 734 (1990); L. C. McDermott and P. S. Shaffer, in The Role of Physics Departments in Preparing K-12 Teachers, edited by G. Buck, J. Hehn, and D. Leslie-Pelecky (American Institute of Physics, College Park, MD, 2000); V. Otero, N.D. Finkelstein, R. McCray, and S. Pollock, Who is responsible for preparing science teachers?, Science 313, 445 (2006); See www.ptec.org for an example of the involvement of professional societies is the Physics Teacher Education Coalition; A chemistry example is illustrated in L. L. Jones, H. Buckler, N. Cooper, and B. Straushein, Preparing preservice chemistry teachers for constructivist classrooms through the use of authentic activities, J. Chem. Educ. 74, 787 (1997).

[2] S. M. Wilson, R. E. Floden, and J. Ferrini-Mundy, Teacher preparation research: An insider's view from the outside, J. Teach. Educ. 53, 190 (2002).

[3] D. D. Goldhaber and D. J. Brewer, Evaluating the effect of teacher degree level on educational performance, in Developments in School Finance, edited by William J. Fowler, Jr. (NCES, Washington, DC, 1996), pp. 197-210.

[4] D. D. Goldhaber and D. J. Brewer, Does teacher certification matter? High school teacher certification status and student achievement, Educ. Eval. Policy Anal. 22, 129 (2000).

[5] D. H. Monk, Subject area preparation of secondary mathematics and science teachers and student achievement, Econ. Educ. Rev. 13, 125 (1994); D. H. Monk and J. King, Multilevel Teacher Resource Effects on Pupil Performance in Secondary Mathematics and Science, in Choices and Consequence, edited by Ronald G. Ehrenberg (ILR Press, Ithaca NY, 1994).

[6] L. Shulman, Those who understand: A conception of teacher knowledge, Educ. Researcher 15, 4 (1986); L. Shulman, Teacher development: Roles of domain expertise and pedagogical knowledge, J. Appl. Dev. Psychol. 21, 129 (2000).

[7] H. Hill, B. Rowan, and D.L. Ball, Effects of teachers' mathematical knowledge for teaching on student achievement, Am. Educ. Res. J. 42, 371 (2005).
[8] For example, one study in mathematics illustrated the lack of mathematical understanding among teachers: L. Ma, Knowing and Teaching Elementary Mathematics: Teachers' Understanding of Fundamental Mathematics in China and the United States (Erlbaum, Mahwah, NH, 1999).

[9] R. Yopp Edwards, "Study of California State University Fullerton multiple subject credential candidate transcripts" (to be published).

[10] There is a wide body of research literature showing that traditionally taught physics courses do relatively little to improve student content understanding. See, for example, many of the articles in the annotated bibliography L.C. McDermott and E.F. Redish, Resource letter: PER-1: Physics education research, Am. J. Phys. 67, 755 (1999); There is also evidence that these courses seem to negatively impact student beliefs about the nature of science and the learning of physics; see E. F. Redish, J. M. Saul, and R. N. Steinberg, Student expectations in introductory physics, Am. J. Phys. 66, 212 (1998).

[11] California Department of Education, Standards for California Public Schools, Kindergarten Through Grade Twelve, 2000, http://www.cde.ca.gov/be/st/ss/.

[12] Candidates can complete a series of courses, but at this point more choose to take a series of standardized tests known as California Subject Examinations for Teachers (CSET), http://www.cset.nesinc.com/.

[13] R. Nanes and J. W. Jewett, Jr., Southern California Area Modern Physics Institute (SCAMPI): A model enhancement program in modern physics for high school teachers, Am. J. Phys. 62, 1020 (1994).

[14] R. diStefano, The IUPP evaluation: What we were trying to learn and how we were trying to learn it, Am. J. Phys. 64, 49 (1996).

[15] R. McCullough, J. McCullough, F. Goldberg, and M. McKean, CPU Workbook (The Learning Team, Armonk, NY, 2001).

[16] J. K. Ono, M.-L. Casem, B. Hoese, A. Houtman, J. Kandel, and E. McClanahan, Development of faculty collaboratives to assess achievement of student learning outcomes in critical thinking in biology core courses, in Proceedings of the National STEM Assessment 
Conference, Washington, DC, 2006, edited by D. Deeds and B. Callen (National Science Foundation and Drury University, 2008), pp. 209-218.

[17] For example, the biology course originally used Biological Sciences Curriculum Study, Biological Perspectives (Kendall-Hunt, Dubuque, IA, 1999).

[18] Neither the biology nor geology course curricula are nationally published, but the courses are still active.

[19] L Pryde Eubanks, C. H. Middlecamp, C. E. Heitzel, and St. W. Keller, Chemistry in Context (American Chemical Society, Washington, DC, 2009), 6th ed.

[20] The representations include some that are similar to the energy bar charts described in A. Van Heuvelen and X. Zou, Multiple representations of work-energy processes, Am. J. Phys. 69, 184 (2001).

[21] The sequence of activities described in this section comes from Vol. 1, chapters 2-4 of the course text, which is described later in Sec. III B (see Ref. [26] for a full citation). The full table of contents is included in Appendix for readers who wish to see how these activities fit into the course as a whole. In particular, this paragraph references activities 2.4.1 (representation of energy), 3.4.1ff (water mixing), and 4.1.1ff (dynamic thermal equilibrium).

[22] R. diStefano, Preliminary IUPP results: Student reactions to in-class demonstrations and to the presentation of coherent themes, Am. J. Phys. 64, 58 (1996).

[23] L.C. McDermott, and the Physics Education Group, Physics by Inquiry (John Wiley \& Sons, Inc., New York, 1996), Vols. I and II; F. Goldberg, V. Otero, and S. Robinson, Physics and Everyday Thinking (It's About Time, Armonk, NY, 2008); American Association of Physics Teachers, Powerful Ideas in Physical Science (AAPT, College Park, MD, 1996), 2nd ed.

[24] In addition to the state K-12 content standards in Ref. [9], see National Committee on Science Education Standards and Assessment, National Research Council, National Science Education Standards (The National Academies Press, Washington, D.C., 1996); California Commission on Teaching Credentialing, Standards of Program Quality and Effectiveness for Subject Matter Requirement for the Multiple Subject Teaching Credential (2001).

[25] The activities are not intended for use with K-8 students, and have not been tested with this population, but some former Phys/Chem 102 students have nevertheless used them to prepare lessons.

[26] F. Goldberg, V. Otero, S. Robinson, R. Kruse, and N. Thompson, Physical Science and Everyday Thinking (It's About Time, Armonk, NY, 2009); See also the LEPS curriculum currently under development, F. Goldberg, E. Price, D. Harlow, S. Robinson, R. Kruse, and M. McKean, AIP Conf. Proc. 1289, 153 (2010).

[27] R. Nanes, Inquiry Into Physical Science: A Contextual Approach (Kendall-Hunt, Dubuque, IA, 2008), Vols. 1-3, 2nd ed.

[28] Some aspects of the implementation at Cal Poly Pomona are described in H. R. Sadaghiani and S. R. Costley, The Effect of an Inquiry-Based Early Field Experience on PreService Teachers' Content Knowledge and Attitudes Toward Teaching, in Physics Education Research
Conference, AIP Conf. Proc. No. 1179 (AIP, New York, 2009) pp. 253-256.

[29] A more formal learning assistant model with extensive accompanying curriculum is described in V. Otero, N. D. Finkelstein, R. McCray, and S. Pollock, Who is responsible for preparing science teachers? (Ref. [1]).

[30] See, for example, R. R. Hake, Interactive-engagement versus traditional methods: A six-thousand-student survey of mechanics test data for introductory physics courses, Am. J. Phys. 66, 64 (1998); Y. J. Dori and J. L. Belcher, How does technology-enabled learning affect undergraduates' understanding of electromagnetic concepts?, J. Learn. Sci. 14, 243 (2005).

[31] D.F. Halpern and M. D. Hakel, Applying the science of learning to the University and beyond: Teaching for longterm retention and transfer, Change 35, 36 (2003).

[32] The course has in the past used the popular text P. Hewitt, Conceptual Physics (Addison-Wesley, Reading, MA, 2001).

[33] Science Content Standards for California Public Schools, Kindergarten through Grade Twelve. The standards are available online at http://www.cde.ca.gov/be/st/ss/ documents/Sciencestnd.pdf Standard $6 \mathrm{~b}$ for Grade 2 (p. 13) includes the measurement of volume. Standards 8a-d for Grade 8 (p. 28) include density and sinking and floating.

[34] See, for example, M. E. Loverude, Investigation of student understanding of hydrostatics and thermal physics and of the underlying concepts from mechanics, Ph.D. thesis, University of Washington, 1999; M. E. Loverude, C. H. Kautz, and P.R.L. Heron, Helping students develop an understanding of Archimedes' principle, Part I: Research on student understanding, Am. J. Phys. 71, 1178 (2003); P. R. L. Heron, M. E. Loverude, and P. S. Shaffer, Helping students develop an understanding of Archimedes' principle, Part II: Development of research-based instructional materials, Am. J. Phys. 71, 1188 (2003).

[35] The original problem on electric charge density is described in S. E. Kanim, Investigation of student difficulties in relating qualitative understanding of electrical phenomena to quantitative problem-solving in physics, Ph.D. thesis, University of Washington, 1999; Questions on mass density adapted from this problem are included in, for example, G. White, Pre-Instruction State of Nonscience Majors-Aspects of Density and Motion, in Proceedings of the 122nd AAPT National Meeting, San Diego, 2001 (Rochester, NY, 2001) and M. E. Loverude, S. E. Kanim, and L. Gomez, Curriculum design for the algebra-based course: Just change the "d's to deltas?," in Physics Education Research Conference, AIP Conf. Proc. 1064 (AIP, New York, 2008), pp. 34-37.

[36] M. E. Loverude, A research-based interactive lecture demonstration on sinking and floating, Am. J. Phys. 77, 897 (2009).

[37] M. E. Loverude, Investigation of student understanding of hydrostatics and thermal physics and of the underlying concepts from mechanics (Ref. [34]); M.E. Loverude, C. H. Kautz, and P. R. L. Heron (Ref. [34]).

[38] See similar findings by K. Cummings, J. Marx, R. Thornton, and D. Kuhl, Evaluating innovation in studio physics, Am. J. Phys. 67, S38 (1999); L. G. Ortiz, 
P.R.L. Heron, and P.S. Shaffer, Investigating student understanding of static equilibrium and accounting for balancing, Am. J. Phys. 73, 545 (2005).

[39] See the state science content standards (Ref. [28]), content standard 1a for grade 5, p. 14.

[40] A paired-samples $t$ test showed a statistically significant gain in the mean percent accuracy on the total PCA and for each stimuli format $(t=10.45, d f=211$, $p \leq 0.05)$.

[41] See state standards, Ref. [8]. The energy questions are covered by grade $9-12$ physics standards $2 \mathrm{a}-\mathrm{c}, \mathrm{p}$. 32 . Heat and temperature are covered by grade 6 standard 3, p. 19. Particulate models of matter are included as early as grade standard 1a, p. 8, with particulate models of different states of matter appearing in grade 8 standard $3 \mathrm{~d}-\mathrm{e}$, p. 27.

[42] This problem and related data are also shown in M. Loverude, Student understanding of gravitational potential energy and the motion of bodies in a gravitational field, Physics Education Research Conference, AIP Conf. Proc. No. 790 (AIP, New York, 2004), pp. $77-80$. 